\title{
A literatura de cordel como patrimônio cultural
}

\author{
[ Cordel literature as cultural heritage
}

Ulpiano T. Bezerra de Meneses ${ }^{\mathrm{I}}$

RESUMO - Encaminhado ao Iphan em 2010 pela Academia Brasileira de Cordel (ABCL), o pedido de registro da literatura de cordel como patrimônio cultural imaterial envolveu um longo processo de pesquisas. O cordel foi tratado como forma de expressão e sistema que se manifesta pela palavra como ação produtiva, na capacidade de gerar efeitos. $O$ voto do relator, após informações básicas sobre a natureza e transformações do bem, centrou-se nas suas dimensões estética, histórica, comunitária e identitária, além de sua extraordinária persistência, como um "conversor de mundos". Incluíram-se propostas de salvaguarda. • PALAVRAS-CHAVE - Literatura de cordel; solicitação de registro; patrimônio cultural imaterial. - ABSTRACT - Forwarded to Iphan in 2010 by the Brazilian Cordel Academy (ABCL), the request for registration of cordel literature as intangible cultural heritage involved a long process of research. The cordel was treated as a form of expression and a system manifested by the productive action, in the capacity to generate effects. The rapporteur's vote, after basic information about the nature and transformations of the good, focused on its aesthetic, historical, communitarian and identity dimensions, as well as its extraordinary persistence, as a "converter of worlds". Safeguard proposals have been included. . KEYWORDS - Cordel literature; registration request; intangible cultural heritage.

Recebido em 20 de dezembro de 2018

Aprovado em 20 de fevereiro de 2019

MENESES, Ulpiano T. Bezerra de. A literatura de cordel como patrimônio cultural. Revista do Instituto de Estudos Brasileiros, Brasil, n. 72, p. 225-244, abr. 2019.

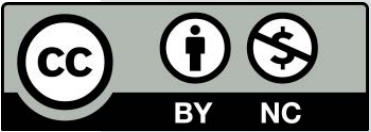

DOI: http://dx.doi.org/Io.II6o6/issn.23I6-90IX.voi72p225-244

I Universidade de São Paulo (USP, São Paulo, SP, Brasil). 
O presente texto não é um artigo acadêmico que pretenda trazer novos conhecimentos sobre o cordel brasileiro. Na verdade - e nisso reside seu interesse próprio - é a transcrição de um documento que, partindo de uma base já definida de conhecimento e tendo sido aprovado pelo Conselho Consultivo do Instituto do Patrimônio Histórico e Artístico Nacional (Iphan), registra especificamente as dimensões culturais que foram consideradas para que, cumprindo requisitos de fundamento constitucional e um longo e demorado ritual, fosse esse bem literário declarado pelo poder público patrimônio cultural imaterial brasileiro.

Subscrito por 85 poetas, o pedido de registro da literatura de cordel como patrimônio imaterial foi encaminhado ao Iphan em 20Io pela Academia Brasileira de Cordel (ABLC). Para análises documentais e de pesquisa, a fim de mobilizar interessados e cumprir exigências legais como a coleta de anuências, realizaram-se inúmeras reuniões de vária natureza.

Com o desenvolvimento desse projeto - de grande porte e alto nível de desempenho -, foi possível a formação de um excepcional banco de dados sobre o cordel, certamente o mais completo do país. Trata-se de uma das iniciativas de maior sucesso no tocante à cultura popular brasileira.

Por se tratar da avaliação da pertinência de um bem como patrimônio cultural, era necessário examinar as exigências legais de contribuição à identidade, memória e ação da sociedade nacional. A conclusão do relatório aprovado reconhece que a literatura de cordel, entendida como arte da palavra poética (principalmente como um extraordinário tradutor de mundos outros), tem deixado, há mais de um século em continuidade, marcas de vária e relevante natureza nas comunidades envolvidas e na vida nacional em geral, além de atuar no presente e prometer futuro, preenchendo, assim, todos os requisitos para ser admitida como patrimônio cultural imaterial brasileiro, pela inscrição no Livro de Registro das Formas de Expressão, tendo como anexo o registro da arte da xilogravura, que lhe é associada. Propostas de salvaguarda também foram aprovadas.

Expõe-se a seguir o meu parecer ${ }^{2}$, como conselheiro do Instituto Histórico e

2 O parecer aqui exposto consta na Ata da 89를 Reunião do Conselho Consultivo do Patrimônio Cultural (IPHAN, 2018, p. 6-26). 
Artístico Nacional (Iphan), sobre a solicitação de registro da literatura de cordel como patrimônio cultural brasileiro.

\section{Processo N. 0I450.008598/2010-20}

Assunto: Solicitação de registro da "Literatura de Cordel” como patrimônio cultural brasileiro

\section{PARECER DO RELATOR}

\section{INTRODUÇÃO}

O pedido de registro da literatura de cordel foi encaminhado ao Iphan em 20Io pela Academia Brasileira de Literatura de Cordel, criada no Rio de Janeiro em I988. Estava subscrito por 85 poetas. Embora considerada pertinente para encaminhamento pela Câmara do Patrimônio Imaterial ainda no mesmo ano, só pôde prosseguir seu curso em 20I3, por falta de recursos, que apenas se tornaram disponíveis com uma emenda parlamentar do Deputado Jean Wyllys.

O CNFCP/Centro Nacional de Folclore e Cultura Popular supervisionou o Inventário Cultural entre 20I3 e 20I7. A Profa. Dra. Rosilene Alves de Melo, da Universidade Federal de Campina Grande e reconhecida especialista do tema, foi chamada a coordenar os conteúdos. A pesquisa mobilizou pesquisadores do Iphan (DPI e Superintendências Regionais pertinentes) e uma vasta rede de instituições (Casa de Rui Barbosa, Fundação Nacional Joaquim Nabuco, IEB/USP, UFPB, UFCA, UFCG, UFRJ), do que resultou vasto levantamento bibliográfico, repertório biográfico de personagens significativas do cordel, relação de coleções públicas e particulares, com centenas de entrevistas e pesquisas de campo que abrangeram os estados do Ceará, Pernambuco, Paraíba, Maranhão, Pará, Rio Grande do Norte, Alagoas, Sergipe, Bahia, Minas Gerais, Rio de Janeiro e São Paulo, além do Distrito Federal.

Foram realizadas inúmeras reuniões de vária natureza, seja para fins documentais e de pesquisa, seja mobilização de interessados, seja ainda para procedimentos exigíveis (como a coleta de anuências). Todos estes esforços produziram um resultado do mais alto interesse. Para resumir, trata-se de um projeto de grande porte e alto nível de desempenho, que tornou possível a formação de um excepcional banco de dados sobre o cordel, certamente o mais completo do país. Não hesito em considerá-lo (ainda mais pela rede de colaboração constituída e que valeria a pena dispor de condições de prosseguir atuante), como uma das iniciativas de maior sucesso no tocante à cultura popular brasileira.

O Dossiê de Registro é um indispensável e competente repositório de informação e pistas para conhecimento do cordel, repositório de que me vali permanentemente, não sendo especialista do tema (apesar de leitor e grande apreciador), em busca dos insumos necessários ao parecer.

O Parecer Técnico, datado de julho último, é da responsabilidade da Dra. Elisabeth Costa, Chefe da Divisão de Pesquisa do CNFCP. 


\section{IDENTIFICAÇÃO DO BEM}

A identificação do cordel como "literatura", apesar de polêmicas, não me causa estranheza, salvo diante de noções redutoras de literatura. Esta, como já ensinava Antonio Candido em I958, deve ser concebida integrando autores, obras, público (leitor, intérprete), suporte de produção e circulação, em um sistema articulado - que não exclui a dimensão de práticas culturais - e não como simples pluralidade aleatória de autores e obras, tratada como independente de uma articulação funcional visível e específica. Literatura e prática do cordel (inclusive na dimensão comunitária) têm em comum o fato de agir sobre nosso mundo pela palavra, com a qual também criam novos mundos. Por isso mesmo, e pela alta qualidade que o cordel é capaz de atingir (independentemente das oscilações individuais que também afetam quaisquer outros domínios literários), considero inexplicável que ele não conste dos manuais de nossa história literária e se veja exilado num contexto desistoricizado de folclore ou arte popular. Por fim, lembre-se que a proposta de registro vem de uma instituição que tem "literatura de cordel” em sua denominação.

Já o termo cordel é ambíguo, primeiro por se associar restritamente à expressão veiculada por escrito, segundo, por supor uma forma de circulação de pequenos folhetos dispostos em espaços de sociabilidade concentrada, como feiras, festas, praças e outros pontos de encontro - o que de fato ocorreu e ocorre - embora a circulação externa a esses espaços venha crescendo. Todavia, que fossem, como padrão, suspensos em cordinhas (daí a denominação) não é atestado como norma corrente, nem como denominação exclusiva, senão a partir de I950s, por influência de Raymond Cantel, um especialista na littérature de colportage. Aliás, as denominações variam segundo várias categorias, conforme o suporte (folheto, “foieto”, livro, folhinha, romance), tradição (folheto antigo), lugar (arrecifes, poesia da rua), editores (livro de Athayde), conteúdo (histórias de João Grilo), origem social (poesia de matuto) e assim por diante.

De todo modo a expressão "cordel” é bastante usual e cômoda para abrigar os múltiplos componentes desse bem.

Pode-se buscar as origens do cordel em tradições narrativas diversas como as que remontam ao trovadorismo medieval, por via da Península Ibérica (cordel português, com sua fisionomia bem distinta do que será nosso cordel), e outras expressões encontradas na Argentina, México, Peru, Venezuela, etc., mas um substrato mais remoto sobre o qual agem todos esses insumos trazidos pelos colonizadores são práticas sonoras comuns a culturas comunitárias, substrato que se expressará, em nosso caso, num patrimônio vocal que carreia heranças europeias, africanas, indígenas e árabes, congregadas numa grande família - objeto recente de reivindicações constantes da Carta do Crato, de 20I4: "o aboio, as cantigas das lavadeiras, das farinhadas e outros trabalhadores do povo, os benditos dos penitentes e das renovações, as peças de reisado, maneiro-pau, maracatu, coco e outros folguedos, o repente ao som da viola, do pandeiro ou do ganzá, os folhetos, versos e romances que constituem o universo da literatura de cordel”. Somente este último, na sua personalidade e trajetória próprias, é que foi objeto da solicitação em exame.

Constam também como antepassados práticas editoriais europeias voltadas para a difusão, em grande escala e em meios populares, de literatura de baixo custo. 
Ivamberto Albuquerque de Oliveira (Dossiê, p. 5I), poeta e estudioso do cordel, falando especificamente da reciclagem pela qual teria passado o cordel português entre nós, diz algo que pode ser generalizado a todos os influxos que constituíram a matéria-prima inicial de nosso cordel: “... os nordestinos pegaram como se fosse um trigo, que dele se extrai vários produtos, o pão, a bolacha, o biscoito e outras coisas mais, desse trigo que veio lá de fora, saiu as cantorias, saiu os poetas populares, saiu os cordelistas, saiu os cantadores de coco e outras coisas mais, dando toda uma roupagem rica, maravilhosa e diversificada no Nordeste brasileiro do que veio lá de fora...”

O que é certo é que o cordel brasileiro começa a ganhar impulso próprio a partir da liberação da impressão local de publicações no reino, a partir de I82I. Esse perfil ganha intensidade no final do século I9. Os primeiros folhetos coletados datam de I890. Leandro Gomes de Barros (I865-I9I8) é considerado o cordelista mais antigo de que se tem notícia. A tradição registrou nomes de outros poetas pioneiros, como Silvino Pirauá Lima, Francisco das Chagas Batista, João Melchiades Ferreira da Silva... Entre I920 e I950 tem-se uma época de ouro, em que o Recife desempenhou papel difusor fundamental. Com o surgimento do rádio de pilha pelos anos I960 e, mais tarde, a expansão da televisão, a produção do cordel foi um tanto irregular, mas impulsionado pela diáspora nordestina em direção à Amazônia e ao Sudeste ele se estendeu geograficamente de forma considerável. A conquista da classe média e da intelectualidade pode situar-se pelos idos de I970 e I980. A entrada no mundo cibernético deu-se em I997. Com todas essas oscilações, crises e superações e assimilação de suportes, o cordel mantém-se vivo e atuante, em diálogo com o curso da história.

\section{ANÁLISE}

O cordel é um mundo de extraordinária fluidez e extensibilidade, que não pode ser apreendido por nenhum campo disciplinar autônomo: antropologia, história, literatura, linguística, comunicação, artes visuais, psicologia, economia, geografia, pedagogia, etc. etc. E nem é minha função articular essas variadas abordagens numa eventual síntese. A solução foi ater-me rigidamente a meu papel de avaliar a pertinência de um bem como patrimônio cultural. E para tanto, o caminho mais prático - e mais confortável - foi seguir a conceituação de patrimônio cultural brasileiro que nos fornece a Constituição de I988. Não que eu seja um garantista e acredite que as normas legais são enunciados que dão conta do mundo e da vida, mas porque, apesar de todas as suas limitações e incoerências o art. 2I6 da nossa lei maior abriu caminhos para agir de forma mais consequente em nosso campo de interesse. Diz o referido artigo: "Constituem patrimônio cultural brasileiro os bens de natureza material e imaterial, tomados individualmente ou em conjunto, portadores de referência à identidade, à ação, à memória dos diferentes grupos formadores da sociedade brasileira..." [seguem-se categorias exemplificativas].

A norma constitucional resolveu, finalmente (ainda que só como norma...) problema demográfico que afligia nosso campo desde sua institucionalização em 1937: a ausência de pessoas. O patrimônio estava fantasmagoricamente povoado de coisas, sempre tratadas como autossuficientes. Ao transferir a matriz do valor cultural do Estado para 
as práticas sociais de identidade e memória, a Constituição introduziu na arena a figura do sujeito, porque somente sujeitos podem exercer identidade e memória.

Sujeitos, e, em decorrência, corpo, identidade, memória, emoção ação: o patrimônio, finalmente, pode se povoar de humanos, mais que isso, de humanos em ação, em interação. Nessa perspectiva resolvi reduzir a complexidade do cordel a dimensões culturais das práticas sociais vividas pelas comunidades implicadas e que fossem pertinentes para responder à conceituação constitucional.

As três primeiras dimensões (expressiva/estética/histórica) dizem respeito ao que seriam as principais características das referências culturais. As três seguintes (dimensão comunitária, memorial-identitária e pragmática) abordam diretamente os efeitos de tais referências.

\section{Dimensão expressiva}

\section{A palavra expressiva}

Quando se fala de cordel, uma das sensações mais correntes é a de sua força como meio de comunicação. Chega-se mesmo a defini-lo desde I980 como "folkcomunicação", isto é, no dizer de Luiz Beltrão (Folkcomunicação, teoria e metodologia), "um mecanismo de comunicação adaptado a demandas locais e receptores de classes menos favorecidas”. É isso também, mas é possível ir além e, para tanto, ampliar o entendimento do cordel como arte da palavra.

A linguagem, como dizem os fenomenologistas, é uma ferramenta que permite trocas do organismo com o mundo que nos envolve e do qual somos parte, segundo o nosso modo de ser nesse mundo, modo corporal. Essa ferramenta é que transforma o sensível da nossa experiência, do viver a vida, em coisa inteligível, em conhecimento, representações, que podem, então, ser comunicadas - carregadas de desejos, motivações, afetos - tornando assim possível o convívio social. Não vou entrar nas disputas que hoje ocorrem entre linguistas que dão prioridade a funções representacionais, cognitivas, comunicacionais, e os pragmatistas, que postulam a linguagem como forma de produção.

O que nos interessa aqui é a linguagem que se realiza na palavra, em todas as suas significações corporais e registros que lhe convierem (escrito, visual, performance, multimeios etc.) e com as diferentes funções à vista, mas sempre incluindo um componente de ação.

Assim, o termo "expressão" não se limita a externalizar, espremendo, algo que estivesse escondido em nosso interior, ou um sumo já existente, mas prisioneiro da fruta. Expressar é uma forma de intervir no mundo. Por isso, conceber o cordel como "forma de expressão" é reconhecer que ele exerce, pela palavra, uma ação produtiva, que não passa em branco, mas tem capacidade de transformar, agindo em todas as frentes possíveis.

Se quisermos ser mais específicos e considerar o cordel uma "arte da palavra", precisamos então esclarecer: arte como uma maneira de fazer, no caso, de fazer falando. Mas arte é uma maneira de fazer bem, não qualquer fazer, não com qualquer palavra, mas com a palavra estética guiada por regras de consenso. 
O vocábulo "palavra" já encerra na origem um sentido de provocação: vem do grego parabollein (que deu também parábola). O verbo bollein quer dizer jogar, atirar; pará, ao lado. Parabollein significa, então, colocar lado a lado, incitando a comparar. Usar a palavra - ato de fala -, na sua configuração de nascença, é não só comunicar algo, mas exigir uma resposta que tirasse consequências do que se apresentou.

É nesse sentido de ferramenta do dizer ativo (do dizer produtor, fecundante) e do dizer com a palavra poética, que entendo o objeto de minha análise.

\section{Cânone}

As regras que criam condições para que a palavra do cordel pudesse ser poética são consideradas explicitamente como fundamentais por seus praticantes. "É bom quando pode obedecer direitinho", diz o poeta Manoel Santamaria (Dossiê, p. 24); "o produto deve ser adequado em todas as regras”, sentencia o poeta Severino Horta (Dossiê, p. 23). Elas não se contentam com talento, exigem aprendizado e aquele domínio que separa os leigos dos poetas: "os leigos não se tocam muito" diz ainda Manoel Santamaria (Dossiê, p. 25), mas as regras devem ser cumpridas. Tais regras, explícitas, foram-se sedimentando aos poucos, até se fixarem numa fórmula simples: métrica, rima e "oração".

"Tudo começa com a métrica", pois, segundo o poeta Expedito Sebastião da Silva (Dossiê, p. 28), “a métrica é o que faz o cordel ficar bonito”. Uma combinação de sílabas poéticas (definidas pela tonicidade, que produz o ritmo), com variação prevista de sua quantidade por verso, versos por sua vez dispostos também em número variável de estrofes, formam as "modalidades" que são muitas, e muito bem definidas; as mais correntes são a parcela, a quadra, a sextilha, a setilha, as oitavas, as décimas, o martelo, o galope à beira-mar e os versos alexandrinos.

A rima, por sua vez exige coincidência total da última sílaba do verso, com outros versos em ordem fixa, mas com várias alternativas, todas elas definidas para cada modalidade. A sonoridade do ritmo e da rima, herança da oralidade, funciona, pois, como teste de competência e qualidade. Canta "por escrito" o cordel "Quer escrever o cordel? Aprenda a fazer fazendo", de Manoel Monteiro: "Fugindo dessas estéticas/ Arranha e fere o ouvido”. Finalmente, tem-se a "oração”, conceito mais sugerido que definido e pouco assimilado: "muita gente não entende bem o que é oração", ao ver do poeta William José Gomes Pinto (Dossiê, p. 26). No entanto é uma chave estratégica, pois a oração exige, de um lado, a sequência aristotélica de início, meio e fim da narrativa, para propiciar o entendimento e, de outro, se destina a provocar emoção. Ivamberto Oliveira (Dossiê, p. 27-8) especifica: "é fazer chorar, fazer rir, fazer refletir".

O "canto" é "tira-prova”, completa Ivamberto (Dossiê, p. 23), pois denuncia o grau de habilitação do poeta. Tem-se, pois, uma aparência de espontaneidade submetida a uma fabricação rigorosamente regrada.

\section{Competições}

Verso do "Galope à beira-mar do cordel e do repente”, de Joel do Carmo Ferreira: "Peleja e repentes são irmãos siameses”; “A peleja é o pai do cordel”, prefere crer o poeta Marcus Lucena (Dossiê, p. 69). 
De fato, o repente, acompanhado de viola, é uma prática oral em que motes propostos pelos circunstantes desafiam a agilidade verbal do cantador. A noção de desafio estará presente também no cordel, agora na disputa de dois poetas. Mesmo sem a força energética da disputa "em presença”, o registro escrito em folhetos continuará a despertar enorme fascínio popular. Debates ao vivo que se tornaram famosos também circularam impressos e há casos de seguidas reimpressões. Uma disputa sempre lembrada é a "Peleja ou Discussão de João Athayde com Leandro Gomes”, sabida de cor e recitada por muitos poetas populares.

Este uso da palavra expressiva para fins de “competição simbólica” teria caráter lúdico, que, como ensina Huizinga (Homo Ludens), é dotado de um fim em si, no caso, como pensam muitos, o gosto do torneio verbal em si. No entanto, os próprios riscos corridos e a intensa demanda de talento e treinamento obrigam a ampliar as indagações. $\mathrm{O}$ esforço continuado aumenta conforme se alteram as convenções do cordel, propondo novas dificuldades, semelhantemente ao que ocorre, por exemplo, nos jogos olímpicos, na ginástica olímpica que só aparentemente é um fim em si.

Jerusa Pires Ferreira (Armadilhas da memória) cita o exemplo da décima corrida ou desmancha para acentuar o rigor do teste, "em que o primeiro cantador constrói e o segundo desmancha, de diante para trás”, e salienta o altíssimo nível de sofisticação e complexidade construtiva colocada na disputa. Não creio que ela seja orientada por conceitos de pragmatismo explícito, de utilidade ou intencionalidade, mas, sem desmerecer o conteúdo lúdico, há efeitos externos recorrentes que devem alimentar, ainda que inconscientemente, algo além do caráter candidamente lúdico. Jerusa também afirma com propriedade que as falas não se contrapõem dialogicamente, mas reforçam o universo monológico, "criando uma espécie de fala para si mesmo, apesar da aparência da disputa”, que às vezes termina em "exercício combinado”. Nessas condições, vejo uma disputa em torno de manejo de regras, não para confrontá-las mas para reafirmar seu valor social classificatório - gerando um efeito implícito que poderia ser entendido como base incipiente de uma difusa ética disciplinar, capaz de provocar admiração, fama e honra. Afinal, o cordel é produtor e difusor de valores e o treinamento para a palavra não deixa de ser, como o esforço investido no esporte, um treinamento para os confrontos da vida.

Roger Caillois (Os jogos e os homens) fala de uma categoria de jogo que é a agonística (agon, palavra sintomática da ética competitiva grega, significa combate e, mais que isso, esforço de combater). O jogo agonístico, como tipo de competição de soma zero, tem um ganhador que procura anular seu rival, forçando-o, no caso do cordel, a cometer um tropeço com verso de pé quebrado ou com hesitação ou demora. A vitória se caracteriza pelo desejo de ver reconhecida a excelência do jogador num determinado domínio, fruto de seu mérito pessoal. Em paralelo, no cordel, creio eu, o agon favorece os processos de autoafirmação, paradoxalmente num quadro de atividade que, por definição, há que ser visceralmente comunitária. Em suma, as disputas geram influxos sociais, distinguindo indivíduos socialmente meritórios, dignos da fama como uma versão da honra tão prezada na moral nordestina. A peleja, porém, não é unanimidade: 
Só sei cantar obra feita

Porque não sou repentista

Sou poeta pensador

Que pouca fama conquista (José Adão - Marco Paraybano).

"Poeta pensador" deve ser aquele que se preocupa com conteúdos, sem contar com as proezas verbais credoras da aceitação social. Contudo, a própria queixa do poeta confirma que a palavra expressiva deixa sempre sua marca no comportamento social. Por isso mesmo creio que as pelejas, que por assim dizer separam os iniciados dos leigos, têm participação na consolidação do papel do autor, com amplas consequências. De todo modo, na peleja, a linguagem se erige em teatro privilegiado das relações e hierarquizações.

\section{Temas}

"Nada é estranho à literatura de cordel”, sentencia o ensaísta Adelino Brandão. É o que se confirma na consulta a uma obra como a de Julie Cavignac e a outros especialistas que procuraram repertoriar os principais temas do cordel, numa lista sem fim, que trata de coronelismo, vaqueiros e cantadores, seca, homens sem medo, cangaço e bandidos justiceiros, heróis culturais, heróis civilizadores, poderes sobrenaturais, revoluções, violência, relações pessoais, sociais, políticas, romances do boi, reinos encantados, mortos bons e mortos maus, culto às almas, almas errantes, vidas exemplares, fases da lua, serpentes, doenças, apocalipse, história antiga, cosmologia, ancestrais, caçadores, princesas, monstros, animais selvagens, luxo, abundância, Padim Ciço, sertão/cidade, etc. Isso sem contar as adaptações de toda sorte de obras literárias e filosóficas, que vão de José de Alencar a Tolstoi, do Leviatã de Hobbes ao Manifesto Comunista de Marx e Engels. Sem contar também a avalanche de casos acontecidos e aquelas notícias do dia, que mal começaram a acontecer, mas já encontraram guarida na generosa palavra narrativa do cordel: “o cordel é um jornal sem patrão”, vangloria-se Raimundo Santa Helena (Dossiê, p. 8).

Que ordem vislumbrar? Que padrões identificar para compreender? Tentativas de classificação por ciclos falharam, por não historicizar adequadamente a presença e o comportamento do cordel. Julgo, porém, que esse generoso e simpático caos deva ser lido numa outra ótica: a da criatividade linguística. A noção foi formulada a partir de uma frase de Humboldt, que muito explica dos limites humanos e sua capacidade de superá-los: “a língua faz usos infinitos de meios finitos”. No meu entender, sem minimamente subestimar as forças históricas de contexto - que ainda não foram suficientemente investigadas e sistematizadas - a criatividade linguística é, sem dúvida, um dos atributos de marca da tradição cordelista.

\section{Dimensão estética}

A palavra do cordel é expressiva, já disse, ela se realiza como nossa experiência do mundo, no nosso modo de ser no mundo, interação essencial. Nesse processo, a palavra sempre tem um papel fundamental, pois ela é que permite que nossos pensamentos, aspirações, expectativas, conceitos, conhecimentos, significados, valores não fiquem 
presos na gaiola da mente, mas se externalizem, sejam trocados, confirmados, contestados, modificados - e ajam. Assim, não há forma básica de se externalizar e levar as trocas adiante se não houver mobilização sensorial, corporal.

A palavra oral, que mobiliza o corpo todo, é esse caminho da vida sensitiva, do sentimento, para promover cognição, emoção, comunicação, ação. Em consequência, a palavra do cordel pode ser chamada de palavra estética, pois ela preenche de maneira aprofundada essa função primordial das trocas de nosso organismo com o mundo, incluindo dimensões materiais e não materiais - como a simbolização e o desejo de transcendência.

Tradição ocidental persistente costuma associar a arte à estética. A estética, porém, é muito mais ampla que a arte, na qual certamente ela precisa estar presente. Convém, assim, recuperar o sentido original do termo, em que o grego aísthesis tem a ver essencialmente com percepção sensorial, portanto, com nossa condição corporal, com aquela ponte insubstituível, há pouco referida, que permite sair de nosso interior para trocas com o mundo exterior - o que inclui a natureza, nossos semelhantes e mesmo o transcendente.

Pode-se dizer, sem exagero, que sem a estética a vida social seria impossível ou gravemente comprometida. O caso historicamente conhecido de Kaspar Hauser, narrado num extraordinário filme de Werner Herzog, é exemplo convincente: mantido desde jovem até a idade adulta numa masmorra com um mínimo de contato verbal, ao se libertar estava inabilitado para a vida social, situação que só foi se alterando quando, como a criança que é enculturada, começou ele a desenvolver o manejo da palavra, só então realizando plenamente sua humanidade.

A palavra gera convívio e é gerada pelo convívio. É ela que assegura a interação social e, nesse processo, qualifica coisas e práticas, estimulando distinções e seleções segundo a presença de atributos capazes de aguçar a percepção. Distinguindo, por exemplo, efeitos instrumentais de efeitos expressivos, isto é, diferenciando (pela experiência, sem precisar racionalizar) o que nos faz entrar em ação e o que nos faz entrar em consciência - ou então, mais comumente, integrando-os unitariamente na mesma coisa ou prática. Os efeitos expressivos é que induzem, no cordel, a que a comunicação seja realizada com mais intensidade, por derivar de um contexto de emoção e afeto. É isso que a métrica e a rima do verso procuram fazer, criando um clima sensível para que a "oração" se complete esteticamente, isto é, mobilize todas as percepções disponíveis para provocar entendimento e emoção.

Não é por acaso que os principais vocábulos usados para definir aspectos do cordel tenham uma carga importantíssima de sensorialidade, corporalidade.

(Entre parênteses: a importância que atribuo a questões etimológicas serve para entender contextos de gestação que permitem explicitar os desenvolvimentos futuros. E também porque estou tratando aqui de um fenômeno do "agir linguístico", em que as palavras são protagonistas privilegiadas.)

O termo verso vem do latim verto/vertere, cujo particípio passado (formador de novas palavras) é versum, oriundo de uma raiz indo-europeia que quer dizer virar, dobrar, escoar, verter: são ações corporais, usadas para designar que o verso, antes de mais nada, existe em dobras, em linhas que, dobradas, garantem unidade de sentido a qual, mais uma vez dobrada, se repete. 
Estrofe é descendente do grego strophé, significando volta, termo associado à agricultura, ao movimento do arado, que vai e volta.

"Oração", o conceito mais curioso com que os cordelistas explicam por que o cordel funciona: funciona, como já vimos, porque o cordelista usa a métrica e a rima para produzir, com a "oração", não só entendimento, mas emoção, afeto. Afeto vem de ad-facere/ad-factum, que quer dizer fazer girar, encostar. Emoção se conecta a e-motus, do verbo movere, mover, tocar. Mesmo num sentido posterior de prece, a oração é um ato de base física - rezar é recitar - quando os lábios se movem em silêncio, mente e corpo misturados.

O cordel é testemunha de que o cotidiano é fonte inesgotável de estética, promovendo aquela "celebração sensual e simbólica da pura materialidade" do dia a dia, de que fala Katya Mandoki ("The sense of earthiness: everyday aesthetics”), salientando a possibilidade de "consciência do maravilhoso no seio do ordinário".

É literalmente apropriado, assim, dizer que a palavra do cordel é palavra corporal, sensorial - em suma, estética - pois ela tem como nos mover, tocar, empurrar, mudar de posição. Ressalte-se que, para o toque, tem que haver proximidade, contiguidade, comunicação o menos intermediada possível. Quando forças históricas promovem intermediação, e as relações costumeiras não são mais cotidianas, a palavra oral perde sua primazia na comunicação simultânea de grande escala, mas permanece numa série de registros dos quais a escrita é de suma importância. A palavra do cordel se realiza originalmente na oralidade, mas, se ela é fruto do seu tempo, que ela também ajuda a plantar, o surgimento da escrita e, depois, de toda a gama diversificada de registros que as sucessivas tecnologias de comunicação geraram, não se pode considerar ter havido perda, mas coparticipação nas transformações históricas, sem jamais renegar as marcas de origem sensorial, corporal.

A leitura do cordel escrito nunca abandonou as funções da métrica e da rima que, como disse acima, guardam a memória da oralidade. Daí que a recitação (mentalizada ou efetiva, individual ou coletiva) seja corrente em várias modalidades, situações e motivações.

Seja como for, a multiplicação de registros ao longo da trajetória histórica garantiu ao cordel extensão de espaço de produção, circulação e fruição, assim como extensão de tempo, seja na fruição individual, seja na sucessão de seu público.

Com a introdução do impresso (de todas as adaptações, a que me parece mais relevante), se há uma perda parcial, a sensorialidade tem outros ganhos. Um deles, que será importante para a própria identidade do cordel, diz respeito ao padrão tipográfico, em que as fontes remontam ao início do século I9 e, mesmo, a fins do I8, exibindo uma pletora de caracteres gráficos, sombras, alternância de caixa-alta e baixa, negritos, vinhetas, filetes, etc., que aparecem na produção de massa em países no caminho incipiente da industrialização (como ocorre com nossos "carimbeiros" e seus rótulos) e sinalizam a presença da competição comercial. Associadas às pequenas irregularidades deixadas pelos processos manuais no papel de baixo custo, fica favorecida uma impressão de coisa antiga, fruto da passagem do tempo como que caucionando a autenticidade. Tal impressão muitas vezes parece ser fruto de propósito explícito, por exemplo, quando toda a capa se apresenta como uma foto de família, reunindo a estirpe inteira de tipos envelhecidos como se fossem as diversas gerações, cada uma com sua fisionomia própria (levantei casos de até dez variações de fontes). 
Com as capas figuradas se abre um novo campo à palavra visual. Ao longo da trajetória do cordel as capas foram incorporando padrões e necessidades da época, que incluem, por exemplo, retratos de cordelistas para garantir direitos autorais, recados e publicidade, cenas de filmes de Hollywood ou linguagens da fotonovela ou das histórias em quadrinho, paisagens de cartão-postal e assim por diante.

A imagem de maior força identitária, todavia, é a das capas destinadas a sintetizar a narração. Força identitária principalmente para o observador externo, que não tem controle da imensa variedade de opções. Como no caso do tema, a impressão de bricolagem deveria suscitar ao analista a procura das lógicas históricas que fariam desse imenso caleidoscópio um quebra-cabeça de alguma inteligibilidade. Entretanto, desconheço se há tentativas de pesquisa nesse sentido.

O que se pode dizer é que as figuras das capas surgiram com funções dêiticas, isto é, a missão de atrair a atenção para fora de si, remetendo ao entrecho, tornando identificáveis à primeira vista (e vista aqui no sentido visual próprio) personagens, ações e suas consequências, devendo eliminar, portanto, tudo aquilo que fosse contingente, evitando o ruído na informação. É claro que várias motivações subjazem a tal propósito publicitário, como a valorização da obra pela ampliação do consumo e o sucesso comercial dos folhetos para manter e desenvolver o sistema econômico em que se insere.

A apreensão oral é de caráter temporal, pois se dá na sequência narrativa das falas, à medida que se desenrola o entrecho, acumulando sentidos parciais, com começo, meio e fim. Já na imagem visual, que passa então a ser explorada, a apreensão, de matriz espacial, ocorre de imediato (Gestalt), gerando a necessidade, para o desenhista, de economizar recursos, potenciando a ação. Não é coincidência que a linguagem abstrata seja dominante, pois ela filtra o excesso de informação e é capaz de estabelecer apenas as articulações essenciais. Também não é por acaso que a xilogravura, entre tantas outras, se tenha tornado a linguagem que vulgarmente remete ao cordel, ignorando sua eclética generosidade. Seja como for, a técnica de entalhes grossos na madeira é a mais apropriada à abstração, estratégia conceitual (e não descritiva), de eficácia pela economia. Como variante, as figuras em contornos preenchidos de cor preta chapada lembram os teatros de sombra da Indonésia, com a mesma função.

Para terminar, valho-me das reflexões de Richard Sennett (O artífice) quanto ao "fazer bem do artesão" como fonte de prazer de origem sensorial, para reiterar a necessidade que temos da sensorialidade, que nos mantenha conscientes de nossa condição humana como condição corporal e pelo prazer de sentir a corporalidade das palavras, dos versos, ritmos, rimas, gestos, posturas, olhares, imagens gráficas e visuais e de toda a matéria transfigurada no cordel.

\section{Dimensão histórica}

Quando se fala da dimensão histórica do cordel, costuma-se de imediato pensar na sua capacidade de representar os processos de transformação da sociedade nacional e principalmente do que virá tardiamente (pós I940s) a ser denominado Nordeste. Por certo estou me referindo a uma certa atitude vulgar muito presente. Assim, frequentemente o cordelista é apresentado como porta-voz do povo, portanto uma via de acesso para 
quem quiser conhecer esse povo. É fora de qualquer dúvida que o cordel é, sim, via de acesso indispensável para o conhecimento da realidade histórica do Nordeste e do restante do país. Não é por retórica, por exemplo, que Mark Curran tenha intitulado uma obra sua de História do Brasil em cordel, e outra, de Retrato do Brasil em cordel. Mas não pela via da representação, não por uma espécie de mimetismo.

A historicidade do cordel não decorre diretamente de uma capacidade mimética. É bom lembrar, com Luiz Costa Lima (Mímesis: desafio ao pensamento), que mimese não é representação de uma matéria social preexistente, mas produção da diferença: força a constituição de uma representação, sim, mas não é reconhecimento, é produção de conhecimento novo.

Nesse sentido, e precisamente nesse sentido, é que o principal conhecimento histórico que o cordel nos fornece é o funcionamento de um universo ficcional - que não precisamos opor a uma verdade objetiva, mas que compõe o jogo dos processos operantes numa sociedade.

A imaginação tem o poder de formar imagens para atender a esta sede de novidade, própria do imaginário, que Bachelard (L’air et les songes) define como a própria essência do psiquismo humano. Mas ele considera mais relevante o poder de nos libertar das imagens primeiras fornecidas pela percepção imediata, deformá-las, transformá-las, não só combiná-las. Tem a função, portanto, de nos ensinar um olhar novo: é preciso constantemente reaprender a olhar. Daí a força política da imaginação, a possibilidade de negar a realidade tal como ela nos é imposta. "A imaginação no poder”: o lema da revolução cultural do Maio de 68 na França poderia ter-se inspirado no cordel.

Assim, para apreender a historicidade do cordel, não é conveniente pensá-lo como documento histórico: convém, antes, “desdocumentalizá-lo”, isto é, livrá-lo de ser tratado como apenas documento e abordá-lo como componente ativo do jogo social. E, para explorar sua singularidade, quanto ao tópico em questão, tomá-lo como formador de padrões do gosto popular além de excepcional produtor e difusor de imaginário em geral na nossa história.

Portanto, critério mais sensato é admitir que o cordel expressa imaginariamente o Nordeste, mas expressa ainda mais a capacidade nordestina de imaginar. Não se trata, porém, de um imaginário homogêneo, mas muitíssimo heterogêneo e tecido de inúmeros fios, trançados com recursos inesgotáveis: do humor ao lúdico, da ironia aos sentidos duplos e justaposições surrealistas e assim por diante.

Para terminar este tópico, julgo prudente reiterar que não resumo a história do cordel a uma história do imaginário, numa versão talvez de uma história das mentalidades atualizada, marginalizando outras dimensões históricas. Estou tão somente procurando desrealizar a realidade nordestina, como diz Messias Moreira Basques Jr., num trabalho sobre o cordel, instigantemente intitulado As verdades da mentira: "O poeta de cordel fabrica as suas histórias ao desrealizar a realidade e os acontecimentos que viu ou ouviu alguém dizer, entretecendo-os com mentiras e acréscimos de retoques que não se pretendem verdadeiros, mas que, ao seu modo, não deixam de sê-lo".

O que é certo é que o cordel é uma fonte inesgotável de conhecimento histórico. 


\section{Dimensão comunitária}

Uma salutar consequência do caráter comunitário que a Constituição vigente reconheceu é que o patrimônio é nacional no sentido de que é do interesse de toda a "sociedade brasileira”, mas já se vê que identidade nacional, memória nacional, história nacional deixam de contar como critérios de suposta integridade e homogeneidade: 0 todo, agora, é a escala de referência para ressaltar a importância das partes.

É fácil reconhecer que o cordel tem uma vocação de natureza comunitária, pois ele só faz sentido em processos relacionais que se caracterizam por certa constância, capaz de dialogar com um contexto histórico, dentro do qual participa das mudanças.

Longe de mim pretender esboçar um panorama das inúmeras configurações que podem ser associadas ao cordel ao longo de sua trajetória. Meu interesse maior é outro: selecionar alguns traços que asseguram ao cordel extraordinária força gravitacional, seu poder agregador, que redunda em configurações de certa estabilidade.

Antes de mais nada, sobretudo em sequência ao surgimento do folheto impresso, a complexa e cerrada rede de produção, circulação, consumo e valorização, com múltiplas combinações de poema, poeta, leitor/ouvinte, editor, desenhista/gravador, distribuidor, apologista, pesquisador/especialista. A integração autor-destinatário é das mais vinculantes e eficazes. São redes de lealdade de fazer inveja à indústria cultural e a qualquer artista erudito.

Enfim, a inclinação associativa do cordel se realiza com entidades de todo tipo que se vêm multiplicando pelo menos desde I95I (com a Associação dos Cantadores do Nordeste, em Fortaleza), congregações de cordelistas, poetas, cantadores, repentistas, trovadores, folheteiros, apologistas, violeiros, isoladamente ou reunidos em grupos variados, que hoje podem chegar a 27. A abrangência nacional é reduzida (duas se apresentam como Academia Brasileira, uma de "cordel”, outra de "literatura de cordel”). As demais são de vínculos regionais, estaduais e mesmo municipais.

Como organismo vivo e comunicacional, o cordel não poderia deixar de se contagiar pelas tecnologias do virtual - o que tem marcado presença sensível nestes últimos tempos e multiplicado os blogs. A questão que se coloca: pode-se falar de comunidades virtuais? Acredito, com Howard Rheingold (The virtual Community: homesteading on the electronic frontier), que sim, como entidades socialmente existentes, agregados sociais que emergem da rede quando um número suficiente de pessoas mantém discussões públicas suficientemente continuadas, com suficiente sensibilidade humana para formar tramas de relações pessoais no ciberespaço.

\section{Dimensão memorial-identitária}

Memória e identidade são processos de personalidade própria que deve ser considerada, mas que na vida vivida se mesclam em dependência simbiótica: as identidades não existem sem memória, e a memória, por sua vez, é fértil geradora das memórias necessárias. Por isso, aqui, elas se apresentam em conjunto.

Começo por observar que o cordel contém em si dispositivos mnemônicos. Não é segredo que a métrica e a rima são, desde a oralidade performática até a oralidade embutida no texto, mecanismos que facilitam a retenção e a memorização. O repente 
esconde na sua aparente imediatez, um estoque de memória considerável. As imagens visuais das capas dos folhetos (e outros traços materiais) também têm função mnemônica.

Mais relevante, porém, é o fato, que me chamou muito a atenção, de que o cordel também se apresenta como uma metalinguagem: o cordel fala do cordel e fala com frequência. São numerosos os poemas que tratam de descrever em versos as regras, justificar as exigências, aspirações e natureza do cordel, explicações de sua retórica, comentários sobre desempenho, fama e gabolices, além de exibir conselhos debates, críticas.

As pelejas, as disputas poéticas, como já exposto, de igual forma, ainda que sutilmente, contêm carga reflexiva muito grande: salientei tratar-se, no fundo, de um combate sobre regras que definem um traço de singularidade.

Um dos efeitos notáveis desse traço reflexivo é o que considero ser uma memória do trabalho: ao desvendar em versos mecanismos de produção do poético (e seus múltiplos efeitos, seja no consumo, seja na valoração do produtor), o cordel contribui para aliviar aquela alienação da mercadoria - mercadoria que ele não deixa de ser. A alienação da mercadoria, já denunciada por Marx, é uma perda da memória de sua produção. "Para entender o que produzimos, temos que ser capazes de lembrá-lo” (Richard Terdiman, Present past: modernity and the memory crisis).

Não é de estranhar que essa consciência que o cordel tem de si mesmo alimente, agora externamente (refiro-me aos seus círculos amplíssimos de pertencimento), uma potente memória pragmática, aquela memória conduzida diretamente à ação: falar em nome do cordel para propor conhecimento e soluções para todo tipo de problemas não é exceção. Finalmente na diáspora nordestina, devida à emigração do Nordeste em direção à Amazônia e, sobretudo, ao Sudeste, nas décadas de I960, I970 e I980, formam-se extensas distâncias geográficas em que os compromissos afetivos e simbólicos com a terra natal não são anulados, mas potenciados. Em decorrência, a portabilidade dos folhetos passa a mediar práticas de memória e identidade, por via de uma cultura portátil que preenche de substância tal Nordeste imaginado.

Esta última observação conduz ao mar proceloso, de naufrágios previsíveis, que é, nos espaços do cordel, o domínio do típico, do estereótipo e de uma caleidoscópica identidade que parece ter sido gerada na bricolagem. Recentemente muitos trabalhos sobre a "invenção do Nordeste" (como os de Durval Muniz de Albuquerque Jr.) têm procurado montar o quebra-cabeça, desmontando essa invenção e as consequências de sua modelagem como fruto de condições históricas e matéria misturada, trazida ou consolidada tanto pelas mais legítimas motivações e aspirações, quanto pelas indústrias do simbólico, pelos interesses ideológicos, políticos econômicos, por juízos de valor negativo (a seca, o banditismo, a pobreza endêmica, o arcaísmo) ou romanticamente paternalista e por tantas outras fontes mais.

Embora seja do maior interesse aquilatar o conteúdo desse Nordeste imaginado como foco de atribuições e funções de referência, não vou me aventurar nesse rumo: para fins de julgamento da pertinência do pedido de registro, tal procedimento não é indispensável. Apenas compete verificar a força das referências, sem necessariamente ter que submeter o foco de atribuições a um suposto teste de verdade empírica ou cientificamente representada. 
Nessas condições, há material suficiente no exposto até aqui para afirmar com segurança que o cordel catalisa fortissimamente funções de referência a um Nordeste em que amplas camadas populares encontram matéria-prima para definir seu lugar no mundo, isto é, no espaço e no tempo, seres históricos que são.

Enfim, não se pode esquecer que a solicitação de registro da literatura de cordel, ela mesmo testemunha um contexto identitário forte. Não excluo motivações legítimas como a competição com outros bens comparáveis já patrimonializados, ou a segurança de continuidade, mas há fundamento mais profundo. Os processos identitários são contrastivos; a fim de se definir não basta a autorreferência, mas o confronto com o outro e, para completar, o reconhecimento externo, como ora solicitado.

\section{Dimensão pragmática}

Para responder ao último quesito de inspiração constitucional, referente à ação do cordel, limitar-me-ei a assinalar três campos em que ele revela sua presença fecundante. Deixo de lado o que já está implícito nas dimensões anteriores.

O uso pedagógico do cordel para estudos da mais ampla temática (história, geografia, agricultura, costumes, tradições, doenças, religiões, etc.) tem aumentado consideravelmente nos últimos tempos no ensino escolar. $\mathrm{O}$ caso que me parece mais consistente, com preocupação teórica e metodológica avançada, é o do letramento, de efeitos promissores já comprovados.

Dispensável é expor o extravasamento do cordel nos últimos anos nas elites culturais, a propósito da cultura popular, como em novelas de televisão (Dias Gomes, p. ex.), música (Gilberto Gil, Ednardo, Alceu Valença...), prosa de ficção (desde Franklin Távora a José Américo, Lins do Rego, Mário de Andrade, Graciliano Ramos, Raquel de Queiroz, Jorge Amado, Guimarães Rosa, Ariano Suassuna), teatro (João Cabral de Melo Neto, Dias Gomes, Suassuna), poesia (Marcus Accioly). Eduardo Diatahy Bezerra de Menezes ("Para uma leitura sociológica da literatura de cordel”), que registrou tal painel, se admira, ainda, dos "inúmeros ensaios de todos os matizes e inclinações que têm sido produzidos atualmente sobre a Literatura de Cordel?”. O Dossiê de Registro assinalou 53 teses de Doutorado ou dissertações de Mestrado, e mais Io monografias ganhadoras do Prêmio Silvio Romero do CNFCP.

Inúmeros outros exemplos da espécie poderiam ser citados, mas me faltava ainda um alcance maior para justificar a força percebida no cordel, sua excepcional agência.

A verdadeira dimensão pragmática do cordel, esse dom de empurrar, de alimentar a possibilidade de ação e transformação só começou a me ficar clara quando me deparei com o "Cordel do software livre”, do cordelista Cárlisson Galdino, nascido em Arapiraca (AL) em I98I, e técnico de computação.

Trata-se de um cordel em setilha de versos de 7 sílabas, estrofes de 7 versos, convenientemente rimados e, no meu entendimento, cumprindo a "oração". Rezam as duas primeiras estrofes: 
Caro amigo que acompanha

Essas linhas que ora escrevo

Sobre um assunto importante

Que até pode causar medo

Mas não é tão complicado

Você vai ficar espantado

Não ter entendido mais cedo

Aqui falo de uma luta

Da mais justa que se viu

Por democratização

Nesse espaço tão hostil

Que é dos computadores

Falo dos novos valores

Que estão tomando o Brasil

Na sequência, o cordelista verseja sobre programas, algoritmos, código fonte, etc. - em suma, dá acesso a informação das mais prosaicas, mas que, no regramento da forma, transmutando termos técnicos em fala cotidiana, de entendimento aberto e peso quase sensorial, por isso mesmo não deixa de tocar, isto é, responder, ressoar, ir além da simples informação. Nada que se compare, é claro, com o grau de emoção no contato com os versos, por exemplo de "A triste partida”, cordel clássico de Patativa do Assaré: mas é da família.

O "Cordel do software aberto" fez surgir em mim a ideia do cordel como conversor, tal qual o Linux, com seu código aberto, de que fala Cárlisson. Cum-verto tem a mesma marca de origem que verso: converter quer dizer "virar-se para junto de": é o que faz seu cordel: traduz, nivelando as diferenças, abre acesso, torna disponível o compartilhamento.

Mas este caminho só se confirmou e amadureceu quando tive acesso a uma ideia luminosa de nossa colega M. Manuela Carneiro da Cunha ("Pontos de vista sobre a floresta amazônica: xamanismo e tradução”), na associação entre o xamã-cosmógrafo da Amazônia e o poeta de cordel: ambos tradutores, utilizam seus recursos para tornar compreensíveis a seus receptores mundos outros, línguas outras.

Penso que a menção a esse aspecto seminal do papel desempenhado pelo cordel dispensa referência a outras notáveis contribuições pontuais que ele tem produzido.

\section{SALVAGUARDAS}

As salvaguardas propostas, todas pertinentes, referem-se aos seguintes temas: manutenção dos vínculos com a oralidade; proteção ao folheto impresso; proteção ao direito autoral; difusão no ambiente escolar. Topicamente se recomendam a recuperação de uma importante referência da história do cordel, a Lira Nordestina, antiga Tipografia São Francisco, de I932, em Juazeiro do Norte/CE; e o apoio ao Portal de Literatura de Cordel do IEB/USP. Há também apelo a cuidados que, sem dúvida, merece a Feira de São Cristóvão, no Rio de Janeiro. 


\section{VOTO}

Todo este longuíssimo caminho percorrido até aqui, quase no passo a passo da subjetividade, dificilmente poderia ser condensado em termos adequados, em virtude do sem-número das facetas do cordel e da amplitude dos sentimentos que ele desencadeia. Se ainda fosse necessário um argumento decisivo para a aceitação do cordel como patrimônio brasileiro, eu o veria nas inúmeras declarações de amor que perpassam depoimentos registrados no Dossiê de Registro e encontráveis em outras tantas fontes que tratam das diversas comunidades que o cordel domina ou contamina.

Falta, porém, para atender ao caráter do registro, definir esse alcance nacional. Espero ter procurado praticar o conselho de Eduardo Viveiros de Castro: se não é possível pensar como eles (eles, aqui, os sujeitos originais das práticas culturais e seus diversos círculos imediatos), ao menos que se pense com eles. Pensar como eles não era possível, pois minha obrigação era produzir um exame anatômico e fisiológico em organismo vivo e bem vivo, dinamicamente vivo. Duvido que poetas cordelistas e apologistas de primeira linha se reconheçam integralmente no retrato anatômico e fisiológico que estou encaminhando a meus pares. Contudo, pensar o cordel fora do cordel, mas pensar o cordel como procurei pensar, sentir que o cordel tem alguma coisa a me dizer, a mim também, é uma forma de "pensar com eles". É também outra maneira de expressar que o cordel tem sempre o que dizer a qualquer um que o procure: assim, o cordel é brasileiro, é de todos os brasileiros, e a exigência da escala de interesse nacional está, portanto, preenchida.

É nesses termos que reconheço a "Literatura de cordel”, entendida como arte da palavra poética (principalmente como um extraordinário tradutor de mundos outros), e por ter deixado há mais de um século em continuidade marcas de vária e relevante natureza nas comunidades envolvidas e na vida nacional em geral, e por atuar no presente e prometer futuro, tendo preenchido todos os requisitos para ser admitida, pelo registro, como patrimônio cultural brasileiro, merece ser inscrita no Livro de Registro das Formas de Expressão. Parece-me adequado incluir no registro o papel da xilogravura, pois entre as técnicas e linguagens visuais foi a que mais se tornou associável ao cordel. É o que proponho à consideração da Sra. Presidente e demais conselheiros.

Rio de Janeiro, I9 de setembro de 2018

Ulpiano T. Bezerra de Meneses

Conselheiro 
ULPIANO T. BEZERRA DE MENESES é professor emérito da Faculdade de Filosofia, Letras e Ciências Humanas da Universidade de São Paulo (FFLCH/USP) e faz parte do Conselho Consultivo do Patrimônio Cultural do Instituto do Patrimônio Histórico e Artístico Nacional (Iphan). E-mail: utbm@uol.com.br https://orcid.org/oooo-0002-4587-2019

\section{REFERÊNCIAS}

ALBUQUERQUE JR. Durval Muniz de. A invenção do Nordeste e outras artes. 5. ed. São Paulo: Cortez, 20II. BACHELARD, Gaston. L'air et les songes: essai sur l'imagination du mouvement. Paris: Le Livre de Poche, I992.

BASQUES JR., Messias M. As verdades da mentira. Ensaio etnográfico com folhetos de cordel. Dissertação (Mestrado em Antropologia Social). Universidade Federal de São Carlos, 2012.

BELTRÃO, Luiz. Folkcomunicação: a comunicação dos marginalizados. São Paulo: Cortez, I980.

BEZERRA DE MENEZES, Eduardo Diatahy. Para uma leitura sociológica da literatura de cordel. Revista de Ciências Sociais (Fortaleza), v. 8, n. I-2, I977, p. 7-87.

CAILLOIS, Roger. Os jogos e os homens: a máscara e a vertigem. Petrópolis: Vozes, 20I7.

CANDIDO, Antonio. Formação da literatura brasileira: momentos decisivos. V. I. São Paulo: Martins, Ig6I.

CANTEL, Raymond. La littérature populaire brésilienne, nouv. éd, revue et augmentée. Poitiers: Centre de Recherches Latino-américaines, 2005.

CAVIGNAC, Julie. A literatura de cordel no Nordeste do Brasil: da história escrita ao relato oral. Natal: Ed. da UFRN, 2006.

CHOMSKY, Noam. Conhecimento da história e construção teórica na linguística moderna. Delta, São Paulo, v. I3, n. especial, I997, p. I33-I55.

CUNHA, M. Manuela Carneiro da. Pontos de vista sobre a floresta amazônica: xamanismo e tradução. Mana, v. 4, I. I, I998, p. 7-22.

CURRAN, Mark J. História do Brasil em cordel. 2. ed. São Paulo: Edusp, 2009. . Retrato do Brasil em cordel. Cotia: Ateliê Editorial, $20 I I$.

FERREIRA, Jerusa Pires. Um gosto de disputa, um combate imaginário. In: . Armadilhas da memória e outros ensaios. Cotia: Ateliê Editorial, 20I2, p. I45-I74.

GALDINO, Carlisson, 20I2. Cordel do software livre. 2 I maio 20I6. Disponível em: 〈http://www.carlissongaldino.com.br/cordel/cordel-do-software-livre>. Acesso em: 8 ago. 2018.

HUIZINGA, Johan. Homo ludens: o jogo como elemento da cultura. São Paulo: Perspectiva, 20I4.

IPHAN - Instituto do Patrimônio Histórico e Artístico Nacional. Ministério da Cultura. Ata da 89a Reunião do Conselho Consultivo do Patrimônio Cultural. Rio de Janeiro - Rio de Janeiro. Ig de setembro de 20I8. Disponível em: 〈http://portal.iphan.gov.br/uploads/atas/ata(3).pdf 〉. Acesso em: jan. 2019. LIMA, Luiz Costa. Mímesis: desafio ao pensamento. Rio de Janeiro: Civilização Brasileira, 2000. 
MANDOKI, Katya. The sense of earthiness: Everyday aesthetics. Diogenes, v. 59, n. I-2, 2013, p. I38-I47.

RHEINHOLD, Howard. The virtual community: homesteading on the electronic frontier. Rev.ed. Cambridge Mass.: MIT Press, 2000.

SENNETT, Richard. The craftsman. New Haven: Yale University Press, 2008.

TERDIMAN, Richard. Present past: modernity and the memory crisis. Ithaca: Cornell University Press, I993. VIVEIROS DE CASTRO, Eduardo. A inconstância da alma selvagem. São Paulo Cosac Naify, 2002. 